\title{
LANGGAM DESAIN KOMUNIKASI VISUAL STUDIO KREATIF MARKETING COMMUNICATION (MARCOMM) DI YOGYAKARTA
}

\author{
Hesti Rahayu \\ Dosen Desain Komunikasi Visual \\ Fakultas Seni Rupa ISI Yogyakarta \\ nadacintaku@gmail.com
}

\begin{abstract}
Creative industry in Indonesia, especially the advertising field in Yogyakarta today is busy with the emergence and dynamic of many marcoms. Researches on advertising approached with the visual communication design have been carried out. Yet, study on the design style has not been done. That is why it is important to scrutinize ads from that angle. This study was conducted to describe and analyze the advertising agencies, mainly the marketing communication creative studios operating in Yogyakarta and also the design styles produced by those marcoms. The research objects were studied by documenting and keenly observing the and interviewing sources. All the gathered data were reselected and analyzed using the Clifford Geertz's Cultural Interpretation Theory and applying the post modernism reflection toward the design development in Indonesia. The result of the study showed that marcoms in Yogyakarta had been started from the advertising as their business core which then were expanded. All marcoms gave different definition on what they considered as their design style based on their concepts and creative ideas. The visual communication design styles were inseparable parts of the cultural transformation process happening which were the integral part of the design world in Indonesia. The styles combined various styles taken from the past and the ethnical styles derived from Indonesian culture style.
\end{abstract}

Keywords: design styles, visual communication design, marcomm, yogyakarta

\section{LATAR BELAKANG MASALAH}

Menggeliatnya industri kreatif khususnya bidang periklanan di Indonesia, saat ini tidak hanya berkembang di ibukota Jakarta saja, tetapi merambah ke kota-kota lain di seluruh Indonesia, tak terkecuali Yogyakarta.

Hingga penelitian ini dibuat, studio kreatif periklanan yang beroperasi di Yogyakarta jumlahnya ratusan, yang sebagian diantaranya telah bergabung secara resmi dalam suatu wadah organisasi PPPI (Persatuan Perusahaan Periklanan
Indonesia). Sementara yang lain belum tergabung tetapi tidak mengurangi esensinya dalam berkiprah di bidang periklanan. Secara umum advertising agensi dan studio kreatif periklanan bergerak dalam bisnis desain grafis, periklanan, dan komunikasi pemasaran lainnya.

Angka sementara pencapaian ekonomi kreatif 2013 (data BPS, statistik ekonomi kreatif 2013) menyatakan sektor ini pertumbuhannya mencapai 5,76 persen, di atas rata-rata pertumbuhan ekonomi 
Indonesia sebesar 5, 74 persen. Kontribusi ekonomi kreatif terhadap PDB Indonesia mencapai Rp 642 triliun, atau 7 persen dari angka nasional (kompas.com/2014/08/24).

Adapun Yogyakarta, merupakan kota dengan berbagai predikat: Jogja Istimewa, Kota Pelajar, Kota Budaya, juga Kota Pariwisata. Semua predikat tersebut menyiratkan bahwa Yogya menyimpan potensi kreatif, yang didukung oleh banyaknya seniman dan karya seni yang dihasilkan. Tak terkecuali di bidang kreatif periklanan, Yogyakarta sangat diperhitungkan di kancah nasional. Orisinalitas ide, penampilan karya iklannya yang banyak mengusung lokalitas, artworknya yang sarat dengan nuansa seni, tak pelak menjadikan Yogyakarta sebagai tempat tujuan baru bagi klien-klien pemilik brandbrand besar untuk menjadikan agensi periklanan Yogyakarta sebagai penggarap komunikasi periklanannya. Hal ini tentu menarik mengingat tren gaya desain komunikasi visual yang berkembang secara global, biasanya akan memberi dampak mewarnai gaya-gaya desain yang dipakai di daerah, tak terkecuali di Yogyakarta.

Kreativitas yang dihasilkan studio marcomm di Yogyakarta memang cukup membanggakan dan memberi harapan, penelitian ini diharapkan dapat memberikan deskripsi dan analisis mengenai apa, siapa, dan bagaimana langgam desain yang diusung marcomm Yogyakarta dalam memberi kontribusi pada dunia periklanan Indonesia, yang secara deskripstif dan analitik menguraikan ide-ide kreatif seperti apa yang dimiliki agensi periklanan di Yogyakarta. Pembahasan mengenai hal ini masih sangat sedikit atau bahkan dapat dikatakan belum pernah dilakukan. Oleh karena itu, tentu topik ini menjadi cukup menarik untuk diteliti.

Tulisan hasil penelitian ini diharapkan dapat memberi gambaran mengenai agensi periklanan berupa studio kreatif marketing communication yang ada di Yogyakarta, serta menjawab bagaimana langgam desain yang lahir dari konsep dan ide-ide kreatif yang dijual oleh studio kreatif marketing communication di Yogyakarta.

Kajian-kajian mengenai periklanan telah banyak dilakukan di bidang keilmuan seni rupa, khususnya Desain Komunikasi Visual, akan tetapi penelitian-penelitian lapangan yang mengkaji mengenai langgam desain khususnya yang ada di Yogyakarta, hampir-hampir belum ada/belum pernah dilakukan. Rata-rata penelitian tersebut hanya membahas visualisasi dan strategi iklan saja dan masih jarang yang membahas mengenai langgam desain, konsep dan ide kreatif. Oleh 
karena itu, posisi penelitian ini sangat penting untuk dilakukan.

\section{LANDASAN TEORI}

Clifford Geertz antara tahun 1952-1954 dan 1957-1958 di kota "Mojokuto" (Jawa Timur) dan Tabanan (Bali) (Geertz, 1973) pernah melakukan penelitian lapangan yang terkemuka berkaitan dengan enterpreneur secara antropologis. Hasil penelitian yang diterbitkan sebagai buku dengan judul "Penjaja dan Raja" ini membahas usaha pengembangan pengusaha pribumi dalam masa peralihan : dari alam tradisional ke alam modern. Penelitian itu menyimpulkan bahwa setiap pengusaha pribumi membawa serta dalam dirinya kekuatan dan kelemahan masing-masing, sesuai dengan lingkungan sosio-budaya tempat mereka berpijak. Penelitian ini menjadi pijakan bagi sebagian ahli antropologi untuk mengadakan penelitian lapangan lebih lanjut agar diperoleh lebih banyak data sebagai landasan untuk menciptakan kebijaksanaan yang lebih realistis. Cara Clifford Geertz dengan Tafsir Budayanya ini dapat diterapkan dalam penelitian ini yaitu dengan menempatkan hubungan antara agency periklanan (marcomm) yang ada di Yogyakarta secara kontekstual dengan lingkungan sosio-budaya tempat marcomm tersebut berkembang.
Agus Sachari dan Yan Yan Sunarya dalam buku Sejarah dan perkembangan Desain dan Dunia Kesenirupaan di Indonesia (2002), menguraikan mengenai desain Indonesia abad ke-21 yang dipengaruhi desain global dan pengaruh posmodern. Ketika membicarakan wacana desain Indonesia, maka Indonesia belum sampai pada tahap membangun identitas khas "desain Indonesia", tidak seperti Korea Selatan, Singapura, Thailand, Taiwan, dan juga Malaysia. Meskipun demikian, desain Indonesia memiliki warnanya sendiri yang menurut Sachari dan Sunarya (2002) dapat disintesiskan sebagai berikut:

Pertama, terdapat dua kutub perkembangan desain di Indonesia, yakni bertolak dari budaya yang mengakar dalam masyarakat Indonesia, dan hasil masukan dari kebudayaan Barat. Perkembangan desain dan seni rupa Indonesia memiliki tiga konsekuensi yang mesti dihadapi yaitu yang tergolong "Posmodernisme palsu (pseudo Postmodernism)", "Posmodernisme tak disadari", atau "Posmodernisme a la Indonesia".

Kedua, terjadi sintesis desain yang berupaya mengantisipasi perubahan tren dunia, dengan memunculkan kembali nasionalisme dan kekuatan pluralitas bangsa. 
Ketiga, tidak relevan jika membandingkan kondisi desain Modernisme dan Posmodernisme di Indonesia, berdasarkan kronologi desain era Modernisme ke Posmodernisme, karena orientasi nilai budaya dalam kebudayaan Indonesia memiliki karakterisktik tanpa harus berkiblat kepada simpulan para pemikir Modernisme dan Posmodernisme di Eropa Barat dan Amerika, sejauh sebagai referensi dan gaya belaka.

Keempat, Desain Indonesia memiliki strategi potong kompas seperti memadukan berbagai gaya desain yang telah lalu dalam sejarah desain, kemudian memadukan International Style dengan gaya etnik dari langgam budaya Indonesia.

\section{METODE PENELITIAN}

Penelitian ini merupakan penelitian yang bersifat deskriptif kualitatif dengan memfokuskan pada studi mengenai langgam desain yang dipakai oleh studio kreatif marcomm yang ada di Yogyakarta.

Adapun untuk dapat mendeskripsikan mengenai fokus studi tersebut di atas, maka dilakukan penelitian lapangan sebagai upaya untuk memperoleh data primer. Selain itu, diperlukan juga penelitian dari berbagai sumber kepustakaan sebagai upaya untuk memperoleh data sekunder. Dalam pendekatan kualitatif, untuk memperoleh data primer tersebut ada dua metode yang digunakan, yaitu:

1) Metode Observasi atau Pengamatan

Teknik yang digunakan dalam melakukan observasi memakai teknik partisipasi terbatas (Vredenbregt, 1978). Observasi dilakukan terhadap objek, yaitu dengan mendokumentasi dan mengamati hasil karya iklan yang dibuat advertising agensi tersebut, serta menjalin rapport yang baik dengan para subjek/ informan (yaitu para praktisi periklanan yang dipilih), melalui kontak via handphone, internet, maupun bertemu langsung, sekaligus melibatkan diri dalam beberapa kegiatan para praktisi ini.

Objek berupa iklan-iklan karya marcomm di Yogyakarta ini dipilih berdasarkan rekomendasi dari para informan. Dalam hal ini berlaku metode purposive sampling (sampel yang dipilih berdasarkan keperluan khusus) yang dianggap dapat memudahkan analisis penelitian.

2) Metode Wawancara

Metode wawancara yang digunakan adalah metode wawancara tak berencana yang tidak berstruktur, bersifat terfokus dan terbuka (Koentjaraningrat, 1997). Dalam penelitian ini informan yang dijadikan sebagai informan kunci adalah praktisi periklanan Yogyakarta 
yang aktif dalam organisasi periklanan (Persatuan Perusahaan Periklanan Indonesia disingkat PPPI) di Yogyakarta. Dengan keterlibatannya sebagai pengurus organisasi, seseorang ini mempunyai jalur koneksi terhadap para praktisi periklanan di seluruh Yogyakarta Dengan demikian lebih mudah dilakukan dan berjalan melalui rekomendasi dari informan kunci.

Para-praktisi periklanan yang direkomendasikan oleh informan kunci keseluruhannya telah diwawancarai. Praktisi periklanan yang dijadikan informan kunci ini harus memenuhi syarat-syarat tertentu agar memudahkan penelitian, yaitu pertama yang bersangkutan masih aktif berkarya atau menjadi pimpinan tim kreatif/ perusahaan periklanan selama kurun waktu 5-10 tahun terakhir; kedua, advertising agensi yang dipimpinnya mempunyai ciri khas dalam menuangkan ide-ide kreatifnya dan teruji secara kualitatif mempunyai keunggulan dalam hal konsep dan strategi kreatif.

Berikutnya data dikerjakan dan dimanfaatkan sedemikian rupa sampai berhasil menyimpulkan kebenaran-kebenaran yang dapat dipakai untuk menjawab persoalan-persoalan yang diajukan dalam penelitian (Koentjaraningrat, 1997).

Dalam penelitian ini, data yang diperoleh disikapi dengan objektif. Walaupun data yang diperoleh akan diedit ulang ataupun diteliti kembali, tetapi tidak akan dikurangi maupun ditambah. Data-data yang terkumpul akan dianalisis secara kualitatif. Keseluruhan data yang diperoleh sebagai hasil observasi, wawancara, dan sumber kepustakaan disusun sesuai kategori-kategori yang sesuai dengan tujuan penelitian sehingga terbentuk suatu pengidentifikasian bagianbagian, mencari keterkaitan antar bagianbagian itu sebagai suatu konsepsi/ struktur sebagaimana yang dikonsepsikan oleh informan. Selanjutnya dari masing-masing kategori ini dikaitkan dan diinterpretasi.

\section{HASIL YANG DICAPAI}

\section{Gambaran Studio Kreatif Marketing Communication di Yogyakarta.}

Seperti yang sudah disebutkan di atas, ada ratusan advertising agensi yang ada di Yogyakarta yang bernaung di bawah organisasi PPPI pengda DIY, akan tetapi dalam penelitian ini sengaja dipilih 3 (tiga) agensi saja yang dianggap dapat merepresentasikan studio kreatif marketing communication (marcomm) di Yogyakarta. Adapun 3 (tiga) agensi marcomm tersebut sebagai berikut:

\section{a. PT. Petakumpet Creative Network}

Perusahaan yang berawal dari nama Studio Angkatan '94 Mahasiswa Desain Komunikasi 
Visual ISI Yogyakarta ini didirikan oleh M. Arief Budiman dan kawan-kawan yang akhirnya resmi menjadi sebuah perusahaan berbadan hukum di tahun 2001 sebagai PT. Petakumpet Creative Network.

Meski menyandang nama yang terkesan bermain-main, tetapi Petakumpet sangat serius dalam menangani bisnisnya, yang melayani Creative Branding, Creative Advertising, dan Creative Consultant.

\section{b. Srengenge Culture Lab}

PT. Srengenge Cipta Imaji, adalah nama yang disandang agensi ini di awal berdirinya di tahun 1999. Bersama dengan kawankawannya, Yazied Syafaat dan Rifki Fauzi mengawali sebuah studio foto atelier (dari bahasa Inggris yang berarti: studio, kamar/tempat kerja, loka cipta) yang berkreasi dengan fotografi. Studio foto yang didirikan ini akhirnya makin berkembang, dari semula menerima pesanan foto-foto produk untuk industri, hingga kemudian departemen kreatif makin memainkan peran penting yang akhirnya menjadi semacam agensi "fotografi desain", berubah lagi menjadi "fotografi dan advertising", hingga akhirnya ketika industri fotografi tidak selalu seperti yang diharapkan, para fotografer perusahaan ini pun akhirnya melepaskan diri. Pada saat itulah akhirnya Srengenge menjadi agensi advertising (tahun 2004), kemudian berkembang menjadi Srengenge Marcomm (tahun 2009), dan di tahun 2012 menemukan eksistensinya yang lebih mantap sebagai Srengenge Culture Lab hingga sekarang.

Dalam bisnisnya, Srengenge Culture Lab menangani 3 (tiga) divisi, yaitu: Divisi Riset, yaitu bagian yang bertugas menangani riset yang berhubungan dengan penggalian consumer insight melalui metode yang etnografis, untuk dapat lebih menyajikan konsep ide yang mengena bagi klien, Divisi Advertising, yaitu divisi yang merupakan basis dasar bisnis Srengenge yang menangani periklanan secara integral (ide, konsep, dan eksekusi), dan Divisi Idea Lab,terbagi dalam 2 (dua) sub-divisi yaitu New Media dan Arxa. New Media menangani proyek-proyek digital (digital imaging, proyek media online, web, dan sebagainya), sedangkan Arxa bertugas melakukan eksplorasi eksperimental pengembangan bisnis perusahaan ke depannya yaitu di bidang furniture, leather, dan fashion.

\section{c. Syafa'at Marcomm}

Pada tahun 1997 Rancang Grafis Syafa'at mulai didirikan. Inilah permulaan bisnis desain grafis yang berkonsep syariah yang kemudian berkembang menjadi Syafa'at Advertising di tahun 2000, dan terus 
merevitalisasi manajemennya hingga menjadi Syafa'at Marcomm di tahun 2010.

Hadir sebagai perusahaan konsultan periklanan yang berbasis syariah, Syafa'at Marcomm berupaya menjawab respon atas pergeseran peradaban yang dihadapkan pada perubahan global yang semakin kompetitif dan semakin cair, menuntut untuk penciptaan sistem periklanan yang efektif, efisien, serta komunikatif dengan dukungan akad-akad yang syar'i.

Sebagai perusahaan yang terus berkembang, Syafa'at Marcomm tengah melebarkan bisnis di bidang penerbitan (Irtikaz Publishing) yang menerbitkan bukubuku Islami, dan merchandise islami (Syuhada Merchandise) yang terdiri dari tshirt, pin, dan sticker.

\section{Langgam Desain Hasil Konsep dan Ide-}

\section{Ide Kreatif Studio Kreatif Marketing}

\section{Communication di Yogyakarta.}

\section{a. PT. Petakumpet Creative Network}

Berdasar wawancara dengan informan, karyakarya Petakumpet yang memiliki langgam desain yang khas adalah karya-karya yang secara visual mengandung local content (muatan lokal/kedaerahan). Bagi Petakumpet, mengerjakan iklan atau karya marcomm dengan muatan lokal memberi tantangan tersendiri karena relatif memberi ruang lebih untuk bervisualisasi dengan lebih ilustratif dan mengekspresikan corak/gaya visual khas Petakumpet. Ini berbeda dengan ketika mengerjakan iklan atau karya marcomm yang sifatnya nasional, karena desain relatif telah di drive/diarahkan dari brand-nya langsung.

\section{b. Srengenge Culture Lab}

Pada iklan dan karya marcomm Srengenge Culture Lab, nuansa lokal tidak selalu terlihat, tetapi sebagai ciri khasnya, iklan-iklan karya Srengenge dibuat dengan lay-out atau tata letak yang cukup menarik. Mereka mengakui bahwa karya-karya iklannya tidak selalu terlihat rigid ataupun detail, dan tidak pula berdasarkan pada konsep yang rumit. Ini diakui oleh mereka karena memang seperti itulah tuntutan klien akhir-akhir ini dan apa yang dapat membuat klien nyaman dan puas, itulah yang mereka lakukan.

\section{c. Syafa'at Marcomm}

Bagi Syafaat Marcomm, karya-karya iklan dan marcomm yang dianggap memiliki langgam atau ciri khas mereka adalah karya yang dilandasi pertimbangan secara syar'i (mempertimbangkan boleh-tidaknya menurut tuntunan agama Islam). Bagi Syafaat Marcomm yang diutamakan adalah aspek syar'i sedangkan kreativitas adalah aspek kedua. 


\section{Hasil Pengamatan dan Analisis Karya}

Langgam desain komunikasi visual karya studio marcomm di Yogyakarta yang diamati melalui karya-karya iklan hasil kreativitas mereka, setidaknya dapat dianalisis melalui beberapa tahapan. Tahap awal dimulai dengan melihat bagaimana perkembangan periklanan di Indonesia secara sekilas untuk dapat melihat posisi dinamis yang terjadi sejak pra kemerdekaan hingga masa kini. Tahap berikutnya adalah melihat bagaimana karya iklan di antara berbagai kepentingan: kepentingan klien, idealisme marcomm agency, dan lokalitas yang harus diusung yang merupakan langgam khusus dari marcomm tersebut. Selanjutnya barulah melihat bagaimana gaya desain dan kompromi desain yang terjadi sehingga dapat disimpulkan adanya langgam tertentu yang dimiliki oleh studio marcomm tersebut.

\section{a. Iklan Indonesia di Tengah Transformasi}

\section{Kebudayaan}

Iklan di Indonesia diakui secara historis dimulai sejak masa Hindia Belanda. Dengan silografi yang ditulis oleh Jan Pieterzoon Coen maka gubernur jenderal itulah yang dianggap sebagai perintis periklanan Indonesia.

Iklan sendiri berasal dari kata i'lan (=bahasa Arab). Bila ditinjau dari etimologinya, reklame dan iklan mempunyai makna yang setara. Iklan dari kata i'lan (=Bahasa Arab) berarti pengumuman, dan reklame berarti seruan yang berulang; maka kedua istilah yang terkait dengan media periklanan ini mengandung makna yang setara yaitu untuk kegiatan penyampaian informasi kepada masyarakat atau khalayak sasaran pesan (http://id.wikipedia.org/wiki/Reklame).

Dalam buku Reka-Reklame, Sejarah Periklanan Indonesia 1744-1984 (Setiyono.ed.: 2004), tercatat ada beberapa fase sejarah periklanan Indonesia yaitu masa penjajahan Belanda, masa depresi ekonomi, masa penjajahan Jepang, masa kemerdekaan, dan masa periklanan Indonesia modern.

Dalam perkembangan berikutnya, dunia periklanan makin berkembang dan akhirnya biro-biro iklan dalam negeri yang didirikan dan dikelola oleh putra bangsa mulai muncul satu-demi satu hingga berjumlah banyak seperti saat ini. Ragam desainnya pun mulai berkembang dan bervariasi, seiring pergeseran dan dinamika kebudayaan di Indonesia. 


\section{b. Iklan di Antara Berbagai Kepentingan :}

Kepentingan Klien, Idealisme Marcomm

\section{Agency, dan Lokalitas}

Karya iklan sebagai suatu karya desain komunikasi visual, merupakan salah satu bagian dalam "keluarga besar" seni rupa. Akan tetapi sebagai karya seni rupa "applied art" atau seni terapan, sebuah karya desain tidak dapat lepas dari kepentingan klien pemesannya. Ini tentu berbeda dibandingkan karya seni rupa murni yang merupakan ekspresi pribadi si seniman. Karya desain komunikasi visual harus dibuat dengan landasan brief klien, dan melalui tahap-tahap yang khas yang pada akhirnya desain iklan yang dihasilkan merupakan hasil kompromi dan solusi yang dirancang oleh desainer.

Adapun tahapan-tahapan perancangan suatu konsep marketing communication dengan luaran berupa iklan dapat digambarkan sebagai berikut:

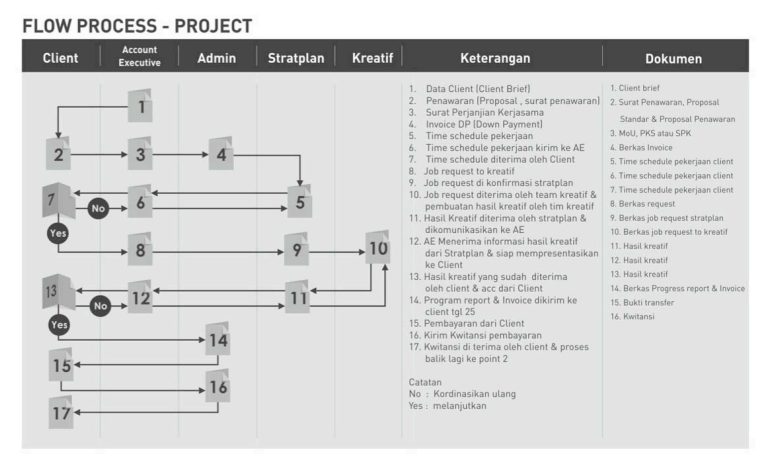

Gambar 1 Bagan flow process-project (dikutip dari Buku Proud of You, 2012)
Dari bagan tersebut di atas nampak bahwa penciptaan karya desain berupa iklan tidak serta-merta hanya mengikuti kehendak desainer, tetapi mungkin akan lebih banyak mengikuti kehendak klien. Inilah yang seringkali dianggap sebagai penyebab bahwa iklan tertentu yang dihasilkan studio marcomm tidak dapat memiliki langgamnya sendiri. Tetapi, masih mengacu pada bagan tersebut, ada poin dimana account executive mempresentasikan hasil kreatif untuk mendapatkan approval dari klien. Poin inilah yang sebenarnya dapat menjadi kunci terjadinya win-win solution antara klien dengan kehendak desainer untuk membuat desain tertentu. Ketika proses ini dapat berjalan baik dan komunikasi lancar, maka dapat dipastikan desain yang tercipta tetap dapat memiliki langgamnya sendiri.

\section{c. Gaya Desain dan Kompromi Desain}

Desain, seharusnya bukan lagi merupakan wahana "propaganda" kebudayaan Barat, dan dijadikan wahana praktis perpanjangan tangan bagi para pelaku ekonomi, melainkan bagaimana menjadikannya sebagai tandatanda peradaban yang bernilai (Sachari, 2002). Inilah yang disebut oleh Sumbo Tinarbuko (2015: 3) bahwa desain komunikasi visual adalah "penanda zaman". Dengan demikian langgam desain 
komunikasi visual yang muncul, menjadi penanda di tiap zamannya.

Untuk menganalisis langgam desain komunikasi visual studio kreatif marcomm di Yogyakarta, pendekatan yang cukup mudah dan sederhana dilakukan dengan menggunakan uraian refleksi posmodernisme yang ditulis oleh Agus Sachari dan Yan Yan Sunarya (2002), yang digunakan sebagai kerangka teori penelitian ini, sebagai berikut:

Pertama, terdapat dua kutub perkembangan desain di Indonesia, yakni bertolak dari budaya yang mengakar dalam masyarakat Indonesia, dan hasil masukan dari kebudayaan Barat. Perkembangan desain dan seni rupa Indonesia memiliki tiga konsekuensi yang mesti dihadapi yaitu yang tergolong "Posmodernisme palsu (pseudo Postmodernism)", "Posmodernisme tak disadari", atau "Posmodernisme ala Indonesia".

Wacana posmodernisme pernah hadir di kancah perdebatan intelektual Indonesia di era 90-an dan kemudian meredup (Sachari \& Sunarya: 2002). Tetapi wacana ini dapat digunakan untuk mencermati kembali jejak desain di Indonesia.

Beberapa contoh iklan karya marcomm di Yogyakarta dapat memberi gambaran seperti misalnya iklan King Komp (pameran komputer) di Jogja Expo Center tahun 2008 lalu yang mengambil idiom kisah masyhur King Kong untuk diplesetkan menjadi King Komp. Kisah King Kong asli, berasal dari Barat tetapi diserap dalam nuansa lokal King Komp yang diselenggarakan di Yogyakarta.

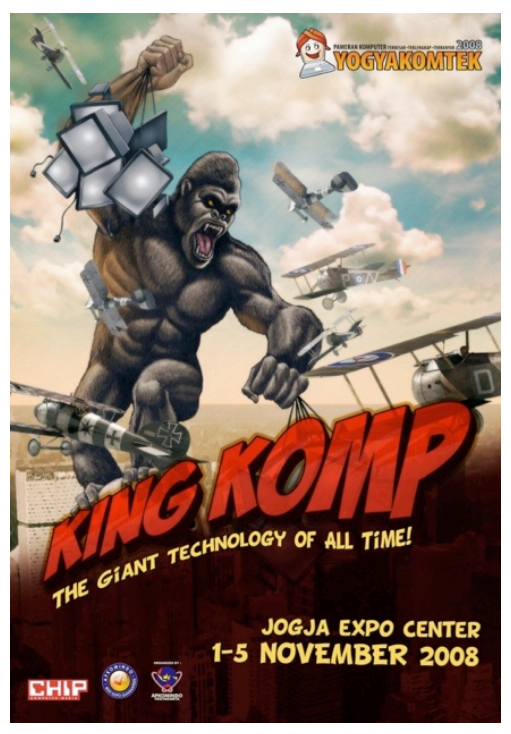

Gambar 2 Iklan Pameran Komputer King Komp karya Petakumpet Creative Network

Kedua, terjadi sintesis desain yang berupaya mengantisipasi perubahan tren dunia, dengan memunculkan kembali nasionalisme dan kekuatan pluralitas bangsa.

Contoh iklan yang dapat menggambarkan point ini misalnya iklan karya Petakumpet untuk Suara Merdeka versi ucapan Paskah ini. Idiom telur paskah merupakan simbol global untuk menggambarkan paskah di seluruh dunia. Tetapi dalam iklan ini visualisasi telur paskah digunakan untuk memberi gambaran pluralitas bangsa Indonesia yang terdiri dari 
berbagai suku bangsa dan agama. Demikian juga iklan Kedaulatan Rakyat versi Hari Raya Imlek karya Petakumpet yang mengusung idiom Barongsai yang merupakan simbol global untuk menggambarkan etnis Tionghoa dan aneka lampion khas Imlek yang diserap dalam nuansa visual bergaya manual.

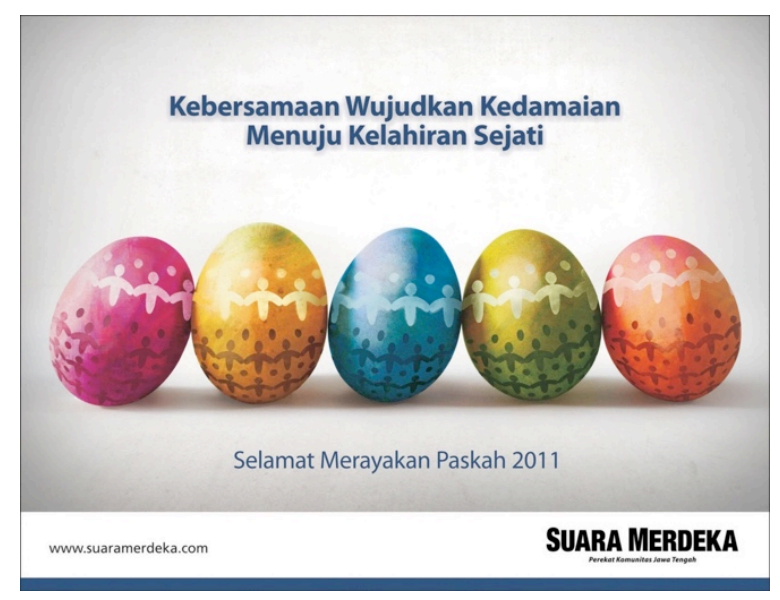

Gambar 3 Iklan Paskah Suara Merdeka karya Petakumpet Creative Network

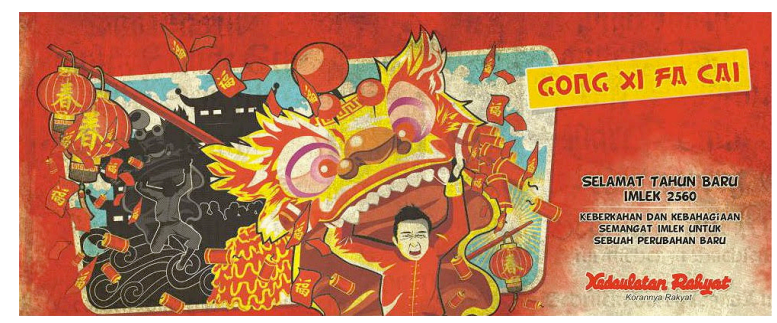

Gambar 4 Iklan Hari Raya Imlek untuk Kedaulatan Rakyat karya Petakumpet Creative Network

Contoh lain misalnya iklan Koran Kedaulatan Rakyat versi Reformasi dan versi Ki Hajar Dewantara di bawah ini yang sangat sarat muatan nasionalismenya. Bagaimana eksistensi Koran Kedaulatan Rakyat dihubungkan sebagai media yang turut membawa pada perubahan bersejarah di Indonesia.

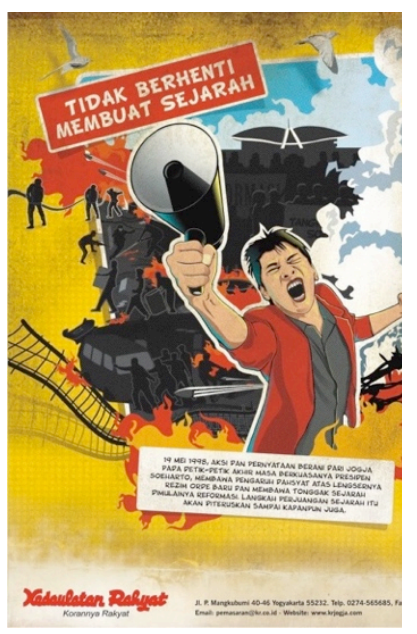

Gambar 5 Iklan Koran Kedaulatan Rakyat versi Reformasi karya Petakumpet

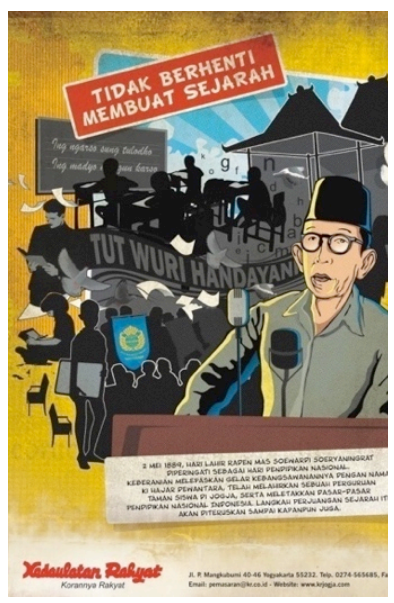

Gambar 6 Iklan Koran Kedaulatan Rakyat versi Ki Hajar karya Petakumpet
Ketiga, tidak relevan jika membandingkan kondisi desain Modernisme dan Posmodernisme di Indonesia, berdasarkan kronologi desain era Modernisme ke Posmodernisme, karena orientasi nilai budaya dalam kebudayaan Indonesia memiliki karakterisktik tanpa harus berkiblat kepada simpulan para pemikir Modernisme dan Posmodernisme di Eropa Barat dan Amerika, sejauh sebagai referensi dan gaya belaka.

Contoh untuk menggambarkan pernyataan di atas dapat kita lihat pada iklan karya Syafa'at Marcomm berikut ini: 


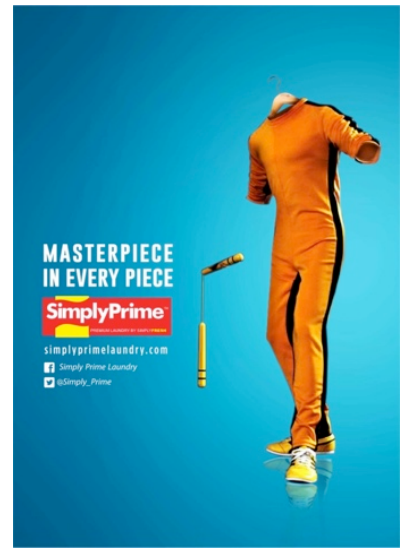

Gambar 7 Print ad Simply Fresh versi Bruce Lee karya Syafa'at Marcomm

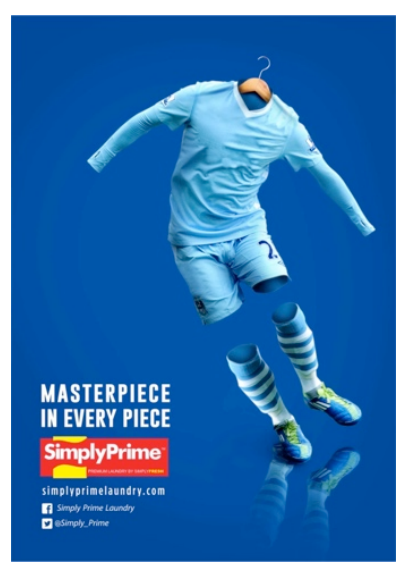

Gambar 8 Print ad Simply Fresh versi Ronaldo, karya Syafa'at Marcomm

Kedua iklan ini meminjam idiom tokoh dunia yaitu Bruce Lee dan Ronaldo yang diserap untuk mengiklankan Simply Prime, sebuah usaha laundry kelas premium yang memberi layanan membersihkan/mencuci baju dengan teknologi khusus. Iklan ini mengusung pesan bahwa jasa laundry ini akan memperlakukan tiap helai baju dengan perlakuan terbaik layaknya sebuah masterpiece.
Visualisasi yang memadukan jasa lokal dengan idiom tokoh terkenal dunia merupakan suatu bentuk pemaduan eklektis khas posmodernisme yang dalam kenyataannya iklan ini dibuat tanpa ada maksud untuk bergaya posmo.

Keempat, Desain Indonesia memiliki strategi potong kompas seperti memadukan berbagai gaya desain yang telah lalu dalam sejarah desain, kemudian memadukan International Style dengan gaya etnik dari langgam budaya Indonesia.

Contoh yang dapat kita lihat misalnya pada iklan Koran Merapi karya Petakumpet yang menggabungkan gaya graffiti (suatu karya seni yang sangat bergaya internasional) dengan idiom-idiom yang bergaya Jawa yang merupakan nama-nama rubrik di koran tersebut. Koran Merapi merupakan anak perusahaan Kedaulatan Rakyat yang menyasar segmentasi menengah-ke bawah, dengan berita-berita ringan seputar kriminalitas, kecelakaan lalu-lintas, klenik, dan sebagainya. 


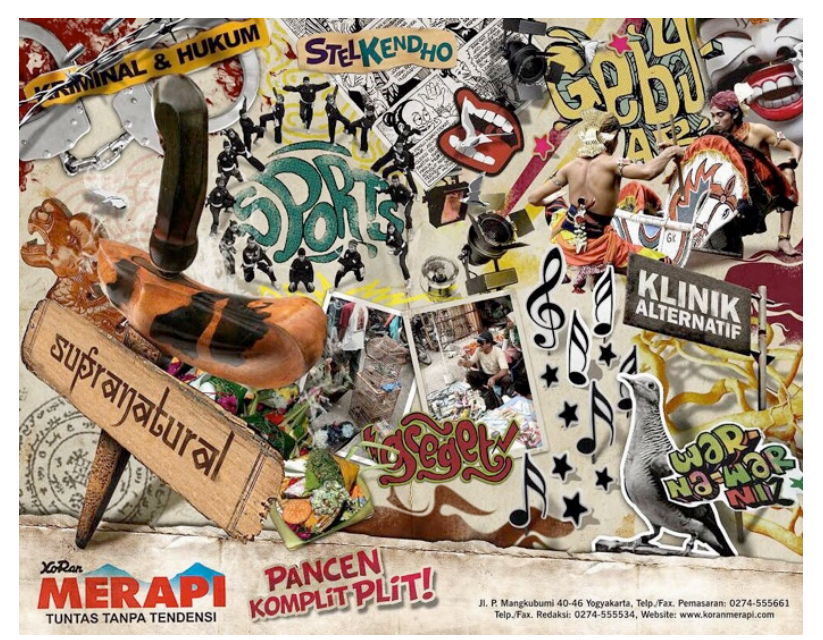

Gambar 9 Iklan Koran Merapi karya Petakumpet Creative Network

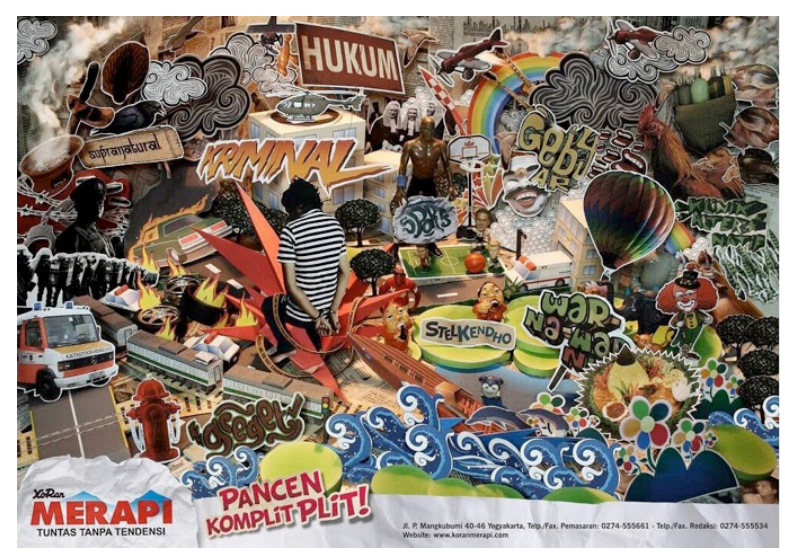

Gambar 10 Iklan Koran Merapi karya Petakumpet Creative Network

Adapun karya-karya lain yang tidak masuk dalam contoh ke empat poin di atas, menurut pengamatan penulis, merupakan karya yang dibuat dengan pertimbangan estetis dan lay-out yang kelokalannya dapat dilihat dari penggunaan model orang Indonesia,serta gaya visual yang tidak dapat dikategorikan ke suatu gaya secara khusus.

\section{KESIMPULAN}

Kesimpulan yang dapat diambil dari penelitian ini adalah sebagai berikut :

1. Agensi periklanan berupa studio kreatif marketing communication yang ada di Yogyakarta terutama yang ada pada sampel merupakan bisnis yang dimulai di awal para pendirinya mengenal bisnis dan menjadi core bussiness yang terus dijalankan dan menghasilkan pengembangan bisnis selanjutnya, contoh:

- Petakumpet Creative Network dari core bussiness Creative Advertising, berkembang ke Creative Branding dan Creative Consultant

- Srengenge Culture Lab, dari core bussiness advertising, berkembang merambah ke divisi riset, dan idea lab yang menangani new media dan pengembangan lanjut secara visioner.

- Syafa'at Marcomm, dari core bussiness advertising, berkembang ke bisnis penerbitan buku dan merchandise islami.

Hal ini mengindikasikan bahwa bisnis marketing communcation yang ada di Yogyakarta akan selalu memberi kontribusi di bidang industri kreatif, dan sejalan dengan namanya, selalu meluas seiring ide-ide kreatif para penggagasnya. 
2. Apa yang dianggap sebagai langgam desain oleh masing-masing agensi kreatif marcomm di Yogyakarta memiliki pengertiannya sendiri-sendiri seiring dengan konsep dan ide-ide kreatif yang lahir dan dijual oleh studio kreatif marketing communication di Yogyakarta.

- Bagi Petakumpet Creative Network, langgam desain yang diangap khas adalah yang mengandung muatan lokal (local conten), yang berciri visual kedaerahan, ilustratif bergaya manual, dan detail.

- Srengenge Culture Lab, menganggap bahwa langgam desain yang dimiliki oleh Srengenge sangat relatif karena mereka lebih berorientasi kepada keinginan klien.

- Syafa'at Marcomm, berpendapat bahwa langgam desain yang khas bagi mereka adalah yang mengutamakan kaidah syar'i, dan menjadikan aspek kreatif sebagai hal yang dinomorduakan setelah aspek syar'i tersebut.

3. Langgam desain komunikasi visual dalam hal ini "dibaca" melalui desain grafis untuk periklanan yang dimiliki masing-masing marcomm agency di Yogyakarta merupakan bagian tak terpisahkan dari proses transformasi budaya yang terjadi di
Indonesia. Pengaruh globalisasi dan posmodernisme menghasilkan sintesis desain yang berupaya mengantisipasi perubahan tren dunia, dengan memunculkan kembali nasionalisme dan kekuatan pluralitas bangsa.

4. Langgam desain komunikasi visual studio kreatif marcomm di Yogyakarta yang merupakan bagian dari dunia desain Indonesia memiliki strategi potong kompas seperti memadukan berbagai gaya desain yang telah lalu dalam sejarah desain, kemudian memadukan International Style dengan gaya etnik dari langgam budaya Indonesia, tanpa harus berkiblat kepada simpulan para pemikir Modernisme dan Posmodernisme di Eropa Barat dan Amerika, sejauh sebagai referensi dan gaya belaka.

\section{DAFTAR PUSTAKA}

[1] Badudu, J.S., 1996. Kamus Umum Bahasa Indonesia, Pustaka Sinar Harapan, Jakarta.

[2] De Bono. Edward. 1988. Berpikir Lateral (terj. Drs. Budi dari judul asli Lateral Thinking), Binarupa Aksara, Jakarta.

[3] Geertz, Clifford. 1973. Penjaja dan Raja (terj.S.Supomo dari judul asli Peddlers and Princess), Gramedia, Jakarta.

[4] Koentjaraningrat. 1997. Metode-metode Penelitian Masyarakat, PT Gramedia Pustaka Utama, Jakarta..

[5] Kelompok Kerja Indonesia Design Power - Departemen Perdagangan. 2008. Pengembangan Ekonomi Kreatif Indonsia 2025, Rencana Pengembangan 
Ekonomi Kreatif Indonesia 2009-2015 Departemen Perdagangan RI.

[6] Moleong, L. 1999. Metodologi penelitian Kualitatif, PT.Rosda Karya, Bandung.

[7] Sairin, Sjafri, Pujo Semedi, Bambang Hudayana. 2002. Pengantar Antropologi Ekonomi, Pustaka Pelajar, Yogyakarta.

[8] Sairin, Sjafri. 2002. Perubahan Sosial Masyarakat Indonesia, Perspektif Antropologi, Pustaka Pelajar, Yogyakarta.

\section{PENELITIAN NON TERBITAN :}

[1] Ahmad Fathurrohman. 2009. Skripsi: Strategi Promosi Biro Iklan Petakumpet Yogyakarta Dalam Menarik Klien, Jurusan Ilmu Komunikasi Fakultas Ilmu Sosial Dan Ilmu Politik Universitas Muhammadiyah Yogyakarta.

[2] Angger Arya Pradana. 2012. Laporan KKM (Kuliah Kerja Media): Visualisasi dalam Periklanan Berbasis Syariah di Syafaat Marcomm, Yogyakarta: Jurusan Komunikasi Terapan, Fakultas ISIP, UNS, Surakarta.

[3] Cahyono, Ekalyptha Setyo. 2005. Skripsi: Strategi Komunikasi Visual Poster Srengenge Advertising Dalam Membentuk Corporate Image Sebagai Biro Iklan (Studi Deskriptif Di Biro Iklan Srengenge Advertising), Jurusan Komunikasi, Universitas Atmajaya Yogyakarta.

[4] Hidayat, Taufik. 2005. Skripsi : Analisis Kepuasan Konsumen terhadap Kualitas pelayanan Jasa pada Syafa'at Advertising Yogyakarta, Jurusan Ekonomi Islam, STAIN-SEM Institute, Yogyakarta.

[5] Riski Aji Probowati. 2009. Skripsi: Strategi Kreatif Iklan Radio Surat Kabar Harian Jogja Oleh Srengenge Advertising (Studi Deskriptif Kualitatif Tentang Strategi Kreatif Iklan Radio Surat Kabar
Harian Jogja Versi Harga Promosi (Rebutan Becak) Oleh Srengenge Advertising),Yogyakarta, Jurusan Ilmu Komunikasi Fakultas Ilmu Sosial Dan Ilmu Politik Univertitas Muhammadiyah Yogyakarta. 